\title{
Investigation the Effects of Boehmite and Gibbsite on the Electrochemical Behaviours of Gel-VRLA Batteries
}

\author{
Metin GENÇTEN \\ Yildiz Technical University, Faculty of Chemical and Metallurgical Engineering, Department of \\ Metallurgy and Materials Engineering, TR34210 Istanbul, Turkey. \\ E-mail: mgencten27@gmail.com
}

doi: $10.20964 / 2018.12 .15$

Received: 16 July 2018 / Accepted: 5 September 2018 / Published: 5 November 2018

In this work, gibbsite and boehmite were used as additives of gel valve regulated lead acid battery for the first time in the literature. Optimum amounts of additives were determined as $0.6 \mathrm{wt} \%$ for each species by using of cyclic voltammetric and electrochemical impedance spectroscopic methods. While anodic peak currents and capacities increased by using of additives, charge transfer resistances decreased. Polarization curves were obtained to determine the effects of additives on the corrosion behaviors of fumed silica based gelled electrolytes. Gel systems consisting of additives showed lower corrosion tendency than those of non-gelled electrolyte and fumed silica based gelled electrolyte. The surface changes of lead electrodes were also analyzed at the end of the 100 voltammetric cycle by scanning electron microscopy. The pictures also supported anti-corrosion (anti-sulfation) effects of additives. These novel additives can be used for manufacturing of fumed silica based gelled electrolyte of valve regulated lead acid batteries.

Keywords: Gel electrolyte, lead acid battery, gibbsite, cyclic voltammetry, electrochemical impedance spectroscopy

\section{FULL TEXT}

(C) 2018 The Authors. Published by ESG (www.electrochemsci.org). This article is an open access article distributed under the terms and conditions of the Creative Commons Attribution license (http://creativecommons.org/licenses/by/4.0/). 